\title{
BEGELEIDING TER VOORKOMING VAN VERMOEIDHEID BY PSIGIATRIESE VERPLEEGKUNDIGES
}

\section{Minrie Greeff, Marie Poggenpoel}

\section{Summary}

Nursing is a stressful activity and therefore it is necessary for nurses to develop fective coping mechanisms, or to strengthen existing ones in a healthy manner, in order to be capable of dealing with stress, arising from their personal and professional lives.

It is, however, not solely stress itself which predisposes nurses to fatigue (physical, psychological and emotional exhaustion) but rather the chronic nature and excessive amount of stressors which place excessive demands on the energy resources and coping, mechanisms of nurses resulting in the ineffective handling of stress which in turn leads to the eventual development of fatigue. The detrimental results of this experience are, however, not confined to the nurse herself, but extends further to the patient and the organization. Thus, if fatigue is not controlled or dealt with, all parties and organizations concerned could suffer.

This research covers the accompaniment function of the psychiatric nurse specialist in the prevention of fatigue in psychiatric nurses by strengthening their mental preparedness.

As a possible solution to the experience of fatigue, a structured, accompanied program of three days was offered to a group of psychiatric nurses. The Solomon four group design was followed in order to eliminate influences on the subjects sulting from the completion of the self-evaluation scale as pre-test.

The data which was obtained from the test results was statistically compared.

Results showed that there was a definite decrease in the levels of fatigue experienced by the experimental group that received the structured accompanied programme, but no real change occured in the control group that had merely been provided with relevant literature.

This meant that the nurses were given the opportunity to learn more effective coping mechanisms to deal with stress arising from their personal and professional lives or to evaluate and strengthen existing ones.

\section{INLEIDING}

Dit is vandag stresvol om binne die verpleegprofessie te staan, want baie hoe eise word aan die verpleegkundiges gesicl ten opsigte van hul funksionering en hul persoon. Tans bestaan daar kommer oor die toename in verpleegkundiges se werksontevredenheid wat nadelig kan wees vir die gehalte van die verpleging wat gelewer word asook vir die verplecgkundige self. Daar is die afgelope aantal jare baje geskryf en bespiegel oor die gevolg hiervan, naamlik die sindroom bekend as uitbranding. Volgens van der Westhuizen (1982:39) is daar al soveel oor die sindroom geskryf en gesê dat die sindroom self al moontlik uitgebrand mag wees. Volgens literatuur verwys die begrip meer na die emosionele druk wat op verplcegkundiges geplaas word as gevolg van die mens - diens professie waarin hulle hulself bevind en word stres as gevolg van die fisiese en psigicse eise buite rekening gelaat. Die werksmilieu van dic verpleegkundige sluit egter meer in as bloot emosionele druk en daarom was daar vir die doel van hierdie navorsing verwys na vermoeidheid in plaas van uitbranding, aangesien die eersgenoemde begrip emosionele, fisiese en psigiese uitputting insluit (Pines, et al., 1981:15).

Hicrdie navorsing het gehandel oor die begeleidingsfunksie van die psigiatriese verpleegspesialis in die voorkoming van vermoeidheid by die psigiatriese verpleegkundiges deur hul geestesparaatheid te versterk.

\section{PROBLEEMSTELLING}

Soos reeds gemeld, is verpleging 'n stresvolle aktiwiteit en daarom het dit nodig geword om metodes te ontwikkel om die stres te hantecr wat ontstaan vanuit die verpleegkundige se persoonlike en professionele lewe. Pines, et al. (1981:16) bevind dat positiewe en negatiewe toestande in die werksomgewing verband hou met vermoeidheid : te veel stres, konflik en eise gekombincer met te min erkenning, vergoeding en sukses. Psigiatriese verpleegkundiges ervaar veral intense interpersoonlike betrokkenheid en gercelde konflik met die pasiënte, gesinslede, genecshere en ander psigiatriese verpleegkundiges. Die meeste van hul interaksies vind plaas binne die verpleegkundige - pasientverhouding en gevolglik is dit minder waarneembaar en is die uitkoms daarvan minder konkreet. Hulle moet daagliks in fisiese, psigiese en emosionelc behoeftes van pasiente voorsien. Daar word van hulle verwag om nie teenoor persoonlike en wcrksprobleme te reageer nie. Verderc eise word gestel deurdat hulle van hulself as professionele persone verwag om alle situasies effektief te kan hanteer (Moore, 1984a:29).

Dic chronicse aard en oormatige hoeveelheid stres asook ongesonde hantering van hierdie stres gce tot vermoeidheid aanleiding en stel hoe eise aan die energiebronne en hanteringsmeganismes van die psigiatriese verpleegkundiges. Supervisie van hierdie verpleegkundiges is meestal funksioneel en nie interpersoonlik van ard nie. Daar is dus 'n gebrek aan professionele ondersteuning en begcleiding.

Indien die verpleegkundiges nie deur die ervaring van vermocidheid begelei word nie kan 
dit ernstige nadelige effek tor gevolg hê soos onder andere vir die persoon self, die pasiènte maar ook vir die organisusie. Dit het dus al hoe nodiger geword om nie slegs vermoeidheid by verpleegkundiges te identifiseer en hulle daarvan bewus te maak nie, maar ook om hulle deur die ervaring te begelei aangesien blote bewusmaking meer stres by verpleegkundiges mag veroorsaak omdat hulle nie weet hoe om hicrdie ervaring te bowe te kom nie en omdat hulle eie hanteringsvermoens bevraagteken word (Greeff, 1986:3).

\section{DOELSTELLINGS VAN DIE NAVORSING}

Om vas te stel of die psigiatriese verpleegkundiges aan vermoeidheid ly, en om vas te stel of die aanbied van 'n gestruktureerde begeleidingsprogram die psigiatriese verpleegkundiges se vlak van vermoeidheid kan verminder en hul geestesparaatheid kan versterk (Greeff, 1986:5).

\section{HIPOTESES VAN DIE NAVORSING}

\section{Nulhipotese (Statistiese hipotese)}

Daar is geen statistiese beduidende verskil in die vlak van vermoeidheid by psigiatriese verpleegkundiges na die aanbied van 'n gestruktureerde begeleidingsprogram aan hulle nie.

\section{Gerigte hipotese}

Die aanbied van 'n gestruktureerde begeleidingsprogram deur 'n psigiatriese verpleegspesialis aan psigiatriese verpleegkundiges wat die ervaring van vermoeidheid beleef, sal hul vlak van vermoeidheid verminder en hul meer in staat stel om hul eie probleme, wat aanleiding gee tot vermoeidheid effektief te hanteer (Greef,1986:6)

\section{DIE NAVORSINGSONTWERP EN -METODE}

\section{Die navorsingsontwerp}

'n Verklarende studie met 'n empiries eksperimentele ontwerp was in hierdie navorsing gevolg en die toepassing van die Solomon-viergroepontwerp was hierby ingeskakel om moontlike voortoets-probleme wat sou ontstaan as gevolg van die gebruik van 'n selfevaluering skaal (meetinstrument) te elimineer (Neale \& Liebert, 1980: 163-163). Twee cksperimentele- en twee kontrole groepe was getrek met behulp van 'n ewekansige steekprocfneming deur middel van loting. Die Blanke psigiatriese verpleegkundiges wat in die psigiatriese eenhede van 'n bepaalde psigiatriese hospital werksaam was, was as proefpersone in hierdie navorsing ingesluit. Die twee eksperimentele groepe het die gestruktureerde begeleidingsprogram ontvang, maar slegs op een was 'n voortoets uitgevoer met behulp van 'n meetinstrument. Dieselfde toets was as 'n natocts uitgevoer op albei die eksperimentele groepe. Did twee kontrole groepe was op 'n soortgelyke wyse hanteer, maar met die verskil dat in die plek van die ingreep hulle slegs ' $n$ leespakket ontvang het om die Hawthorne-effek teen te werk (sien figuur 1) (Greeff, 1986:6-7).

Steekproefbepaling en -neming

Aangesien die populasic van die procfpersone
Figuur 1 Die Solomon-viergroepontwerp

$\begin{array}{lllll}R & 01 & X & 02 & (E 1) \\ R & 03 & & 04 & (K 1) \\ R & & X & 05 & (E 2) \\ R & & & 06 & (K 2) \\ & & & & \end{array}$

(Neale \& Liebert, $1980: 164)$.

vir hierdie navorsing klein was, was die totale populasie as steekproef ingesluit. Weens die Solomon-viergroepontwerp wat in hierdie navorsing gevolg was, was twee eksperimentele-sowel as twee kontrole groepe nodig en was dit nodig om die groepe cwekansig in ewe groot groepe te verdeel deur middel van die proses van loting (Uys \& Basson, 1983:97).

\section{Die meetinstrument}

Die meetinstrument (selfevalueringskaal) wat vir hierdie navorsing ontwerp was, is vir dic bepaling van die psigiatriese verpleegkundiges se vlak van vermoeidheid en staan bekend as die vermoeidheidsvlak-bepalingsvraelys vir verpleegkundiges (Greeff, 1986:143-146)

Vermoeidheidsvlakke word as volg vertolk:

$$
\begin{aligned}
& 28 \cdot 41=\text { Baie lig vermoeid } \\
& 41 \cdot 50=\text { Ligte vermoeidheid } \\
& 51-59=\text { Matige vermoeidheid } \\
& 60 \cdot 68=\text { Vermoeid } \text { - minus } \\
& 69 \cdot 80=\text { Vermoeid } \\
& 81 \cdot 98=\text { Vermoeid }- \text { plus } \\
& 99-110=\text { Erge vermoeidheid } \\
& 111-125=\text { Ernstige vermoeidheid } \\
& 126-196=\text { Hoé risiko vir }
\end{aligned}
$$

(Greetf, 1986:98).

Bogenoemde vertolking van die vraelys is op geen stadium aan die proefpersone beskikbaar gestel nie en dit is slegs deur die navorser aan die einde van die navorsing gebruik om te help met die vertolking van die navorsingsdata.

(Sien die opvolg artikel vir die volledige bespreking van die ontwikkeling van die meetinstrument)

\section{TERMINOLOGIE}

Die volgende terme word in hierdie navorsing gebruik:

\section{Vermoeidheid}

Vermoeidheid is die ervaring van fisiese, psigiese en emosionele uitputting wat by ' $n$ individu ontstaan as gevolg van enige verlengde chroniese stres (fisicse, psigiese en/of emosionele druk) wat nie op 'n gesonde wyse hanteer of verwerk is nie, of as gevolg van ' $n$ skielike verandering soos 'n traumatiese gebeurtenis wat by ' $n$ individu kan voorkom Dit word gekenmerk deur die individu se ontkenning van homself, die omgewing en die lewe (Pines, ct al., 1981:202)

\section{Uitbranding}

Uitbranding stem ooreen met vermocidheid ten opsigte van definisie en simptomatologie, maar dit is uniek ten opsigte van die oorsprong wat in die geval van uitbranding spruit uil die konstante en die herhalende emosionele druk wat gessosieer word met die individue wat met mense werk wat emosioneel veeleisend is en intense betrokkenheid oor lang periodes vereis (Pines, et al. 1981:202)

Ten opsigte van simptomatologie is daar ' $n$ interverwantskap en gelykstelling tussen die twee bogenoemde begrippe, maar daar bestaan essensieel 'n verskil in hul oorsprong (Pines, et al., 1981:15). Om dus verwarring uit te skakel en konsckwentheid te verseker, was daar vir die doel van hierdie navorsing na vermocidheid en uitbranding as sinonieme terme verwys, aangesien die hantering van albei op dieselfde beginsels berus. Slegs die begrip vermoeidheid was gebruik (Greeff, 1986:9)

\section{Geestesparaatheid}

Odendal, Schonees, Swanepoel, Du Toit en Booysen (1983:802) omskryf paraathe s gereedheid of voorbereidherd. Geestesparaatheid kan dus omskryf word as die psigiese en lof emosionele gereedheid of voorbereidheid van ' $n$ individu om die alledaagse stres en werkstres op so 'n gesonde wyse te kan hanteer en verwerk dat oormatige stres nie kan lei tot vermocidheid nie (Greeff, 1986:9).

\section{Begeleiding}

Begeleiding behels alle handelinge wat daarop gerig is om dit vir die begeleide moontlik te maak om haar'sy hulp en steunbehoewendheid, haar/sy vasgelopenheid in haarlsy gesitueerdheid, te oorwin. Dit sluit in:

(a) hulpverlenendc steungewende leiding meedeel van kennis; voorbeeld en voorlecf; prakties voordoen; skep van oefen moontlikhede; aanmoediging tot volharding in die verwerwing van vaardighede vir betekenisvolle selfversorging (-handeling) en 1 sel fstandigheid; en

(b) die oprocp en steun tot singewing en die aanvaarding van verantwoordelikheid (Kotzé, 1979:294).

\section{Stres}

Stres is 'n universele verskynsel wat dui op 'n fisiese en emosionele staat wat altyd as gevolg van die lewe in ' $n$ individu tcenwoordig is. Dil word in 'n nie-spesifieke respons geintensifiseer tot 'n interne of eksterne omgewingsverandering of bedreiging en hierdie respons mag aangepas of wanaangepas wees (Du Toit, 1986:26; Murray \& Huelskoctter. 1983:374).

\section{Psigiatriese Verpleegspesialis}

Die psigiatriese verpleegspesialis is ' $n$ verpleegkundige met 'n meestersgraad in Psigiatriese-

Geestesgesondheidsverpleegkunde, me addisionele begeleide kliniese ervaring en met in diepte kennis en vaardigheid in die praktisering van Psigiatriese en Geestesgesondheidsverpleging (Critchley \& Maurin, 1985:16). 


\section{DIE INSAMELING VAN GEGEWENS}

Die psigiatriese verpleegkundiges het altyd self die selfevalueringskaal voltooi. Die navorser het ook self die voor- en natoetse van die eksperimentele groep afgeneem. Twee psigiatriese verpleegdosente het die voor- en natoetse van die kontrole groep waargeneem. Individuele psigiatriese verpleegkundiges was deur middel van 'n syfertoekenning geìdentifiseer en gedeeltelike anominiteit was dus toegepas (Greeff, 1986:99).

\section{DIE INGREEP BY DIE EKSPERIMENTELE GROEP}

Die gestruktureerde begeleidingsprogram

'n Gestruktureerde begeleidingsprogram was saamgestel deur eers 'n situasie-analise uit te voer om gemeenskaplike stressors te bepaal en dit as riglyn te gebruik in die samestelling van die program (Greeff, 1986:99-100).

Vanuit die literatuurstudie en stressorsituasie-analise was 'n driedaagse ruktureerde begeleidingsprogram mgestel om aan die psigiatriese verpleegkundiges te bied.

Die indeling van die gestruktureerde begeledingsprogram het op dié van Pines, et al. $(1981: 9,103)$ berus en het die psigiatriese verpleegkundiges deur die proses geneem van:

(a) bewusmaking;

(b) die neem van helderheid, en

(c) kognitiewe helderheid, en

(d) die ontwikkeling van hanteringsvaardighede

Laasgenoemde weer ingedeel volgens:

(i) die ontwikkeling van hanteringstrategieë as psigiatriese verpleegkundiges binne 'n burokratiese organisasie;

(ii) die evaluering en uitbreiding van sosiale en werksondersteuningstelsels, en

(iii)die ontwikkeling van intrapersoonlike hantcringstrategieë (Greeff, 1986: 100-101).

\section{Die Kursusinhoud}

Vervolgens 'n kernagtige uiteensetting van die kursusinhoud. Die volledige gestruktureerde begeleidingsprogram word in bylaag $3: 150$ van Greeff, 1986 uiteengesit).

Dag 1

Eenheid A : Bewusmaking

Eenheid B : Die neem van verantwoordelikheid

Eenheid C: Kognitiewe helderheid

Eenheid D : Die ontwikkeling van hanteringsvaardighede

(1) Die ontwikkeling van hanteringstrategieë as individu binne 'n burokratiese organisasie

Dag 2

(2) Die evaluering en uitbreiding van sosiale en werksonderstcuningstelsels.
(3) Die ontwikkeling van intrapersoonlike hanteringstrategieë.

Dag 3

(4) Die ontwikkeling van

intrapersoonlike

hanteringstrategieë (vervolg).

Die aanbied van die gestruktureerde begeleidingsprogram

Die eksperimentele groepe het mekaar weekliks opgevolg vir 'n periode van vier weke, waarin elke groep van vier psigiatriese verpleegkundiges 'n gestruktureerde begeleidingsprogram deurloop het. Die E1 groep het die selfevalueringskaal onmiddellik met die aanvang van die kursus as voortoets voltooi en presies veertien dae later is dieselfde selfevalueringskaal as natoets herhaal. Die E2 groep het slegs die selfevalueringskaal as natoets voltooi presies veertien dae na die aanvang van die kursus. Die gestruktureerde begeledingsprogram is op 'n groep sowel as op 'n individuele begeleidingsmodel geskoei. Elke psigiatriese verpleegkundige het dus aan die begin van die kursus 'n eie kursushandleiding ontvang. Alle oefeninge was voorafgegaan deur ' $n$ kernlesing (teorctiese raamwerk). Die psigiatriese verpleegspesialis was te alle tye teenwoordig om op verskillende vlakke van begeleding in te tree al dan nic (Greeff, 1986:103).

\section{DIE INGREEP BY DIE KONTROLE GROEP}

In 'n poging om die Hawthorne-effek te omseil was aan die kontrole groep 'n leespakket voorsien. Dieselfde selfevalueringskaal was as voortoets op die K1-groep toegepas, en dieselfde tydsverloop van veertien dae was gevolg. Op beide groepe $\mathrm{K} 1$ en $\mathrm{K} 2$ was 'n natoets met dieselfde selfevalueringskaal uitgevoer.

Die tydsverloop tussen die voor-en natoctse van die eksperimentele en kontrole groepe was dus presies dieselfde (Greeff, 1986:103-104).

\section{DIE BESPREKING VAN DIE NAVORSINGSRESULTA'TE}

(Sien tabel 1 vir die toetsresultate verkry na voltooiing van die selfevalueringskaal).

Die navorsingsresultate dui daarop dat beide eksperimentele groepe (E1 - natoets en E2 natoets) 'n statistiese beduidende afname (op die $5 \%$ vlak) in hul vermocidheidsvlakke op die natoetse getoon het, terwyl die kontrole groepe (K1 - natoets en $\mathrm{K} 2$ natoets) geen statistiese beduidende afname (op die $5 \%$ vlak) in hul vermoeidhcidsvlakke getoon het nie (sien figuur 3 ) (Grceff, 1986:118).

Die resultate verkry vanaf die vergelyking van onafhanklike groepe

Nadat die F-1octs (Downie \& Heath, 1970:183) op die drie onderskeic onafhanklike groepe (E1-voortoets en K1-voortoets, E1-natoets met K1-natoets en E1-natoets met K2-natoets) uitgevoer is, het die resultate getoon dat die variansies van die gemiddeldes van die eerste twee gemelde groepe verskil en dus nie homogeen was nie. Dic Welch-toets (Pearson \& Hartley, 1984:27) moes dus op hierdie onafhanklike groepe toegepas word. Die
Tabel 1

Toetsresultate verkry deur die proefpersone na voltooling van dle selfevalueringskasl (meetinstrument)

\begin{tabular}{|c|c|}
\hline E1-VOORTOETS & K1-VOORTOETS \\
\hline 118 & 77 \\
110 & 64 \\
74 & 82 \\
74 & 83 \\
55 & 85 \\
70 & 54 \\
51 & 60 \\
56 & 71 \\
\hline
\end{tabular}

\begin{tabular}{|c|c|}
\hline E1-NATOETS & K1-NATOETS \\
\hline 81 & 71 \\
62 & 69 \\
60 & 81 \\
54 & 102 \\
48 & 130 \\
55 & 49 \\
48 & 66 \\
54 & 71 \\
\hline
\end{tabular}

\begin{tabular}{|c|c|}
\hline E2-NATOETS & K2-NATOETS \\
\hline 36 & 108 \\
45 & 48 \\
75 & 61 \\
66 & 83 \\
47 & 112 \\
36 & 57 \\
45 & 100 \\
88 & 84 \\
\hline
\end{tabular}

vergelyking van die E2-natoets met die K2-natoets het met die F-toets wel getoon dat hierdie onafhanklike groepe homogeen was en die t-toets (Downie \& Heath, 1970:85) vir onafhanklike groepe kon dus op die laasgenoemde onafhanklike groepe toegepas word.

Die t-toets vir onafhanklike groepe en die Welch-toets het na verwerking aangetoon dat daar by die onafhanklike groepe (E1-natoets met K1-natoets en E2-natoets) waar die ingreep (gestruktureerde begeleidingsprogram) op die eksperimentele groepe toegepas is, 'n statistiese beduidende afname (op die 5\% vlak) in die gemiddeldes van die eksperimentele groepe was en die nulhipoteses dus verwerp kon word. Die E1-voortoets en die K1-voortoets het geen statisties beduidende verskil (op die 5\% vlak) in hul gemiddeldes getoon nie en dus het die groepe ooreengestem ten opsigte van die gemiddeldes van hul vermoeidheidsvlakke.

Dit wil sê, die ingreep by die eksperimentele groepe het 'n afname in die vermoeidheidsvlakke van die psigiatriese verpleegkundiges in die eksperimentele groepe tot gevolg gehad. Veranderinge binne die eksperimentele groepe is verder en in minder as $5 \%$ van die gevalle toe te skryf aan blote toeval. By die kontrole groepc (sonder die ingreep) was daar nie 'n statisties beduidende afname (op die $5 \%$ vlak) in die gemiddeldes van hul vermoeidheidsvlakke nie, alhoewel daar wel 'n mate van toename in hierdie gemiddeldes was, 
Figuur 3

Dle Solomon-vlergroepontwerp soos van toepassing op hierdie navorsing

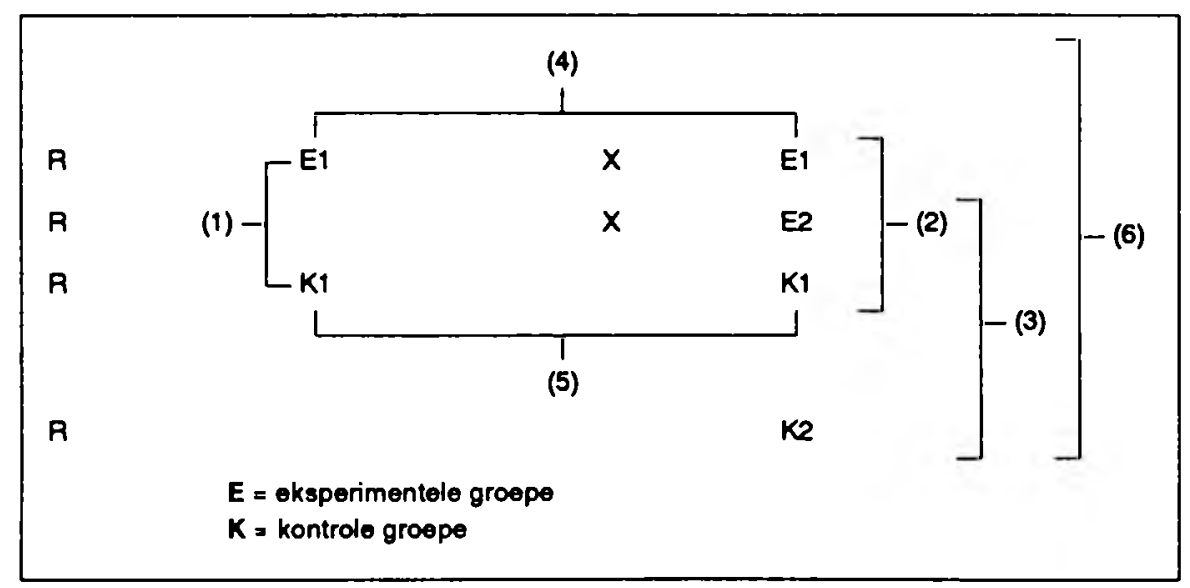

(Greetf, 1986: 109).

maar wat nie statistics beduidend (op die $5 \%$ vlak) was nie (Greeff, 1986:119).

Die resultate verkry vanaf die vergelyking van afhanklike groepe

Die t-toets vir afhanklike groepe (Huysamen, 1976:146) dui aan dat daat by die eksperimentele groep (E1-voortoets), na die ingreep, 'n statisties beduidende afname (op die $5 \%$ vlak) in die gemiddeldes van die voor-tot die natoets (E1-natoets) was, terwyl dit nie die geval by die kontrole groepe (K1-voortoets tot K1-natoets), sonder die ingreep, was nie. Die nulhipotese is dus in die geval van die eksperimentele groepe verwerp, maar by die kontrole groepe aanvaar. Die ingreep by die eksperimentele groepe het gevolglik 'n statisties beduidende afname (op die 5\% vlak) in die vermoeidheidsvlak van die psigiatriese verpleegkundiges tot gevolg gehad terwyl daar geen statisties beduidende afname (op die $5 \%$ vlak) van vermoeidheid by die psigiatriese verpleegkundiges in die kontrole groepe plaasgevind het nie (Greeff, 1986:120).

\section{Gevolgtrekkings}

Psigiatriese verpleegkundiges was wel vermoeid, aangesien beide die eksperimentele en kontrole groepe se proefpersone vermoeidheid ervaar het in die voortoetse.

Die ingreep (gestruktureerde begeledingsprogram) het ' $n$ besliste afname in die vermoeidheidsvlak van die psigiatriese verpleegkundiges in die eksperimentele groep tot gevolg gehad deur te verskuif vanaf die kategorie vermoeid : 69 - 80 verby vermoeid-minus na die kategorie matig vermoeid : 51 - 59 .

Alhoewel die meetinstrument 'n selfevalueringskaal was het dit nie die toetsresultate besoedel as gevolg van 'n mate van subjektiwiteit by proefpersone nie, aangesien albei die eksperimentele groepe verwagte statisties beduidende afnames (op die $5 \%$ vlak) getoon het, en beide kontrole groepe volgens verwagting geen statisties beduidende afname (op die $5 \%$ vlak) in gemiddeldes getoon het nie. Dit bevestig slegs die betroubaarheid en geldigheid van die selfevalueringskaal as effektiewe meetinstrument in die identifisering van vermoeidheidsvlakke sowel as 'n af name of toename daarin.
In totaliteit kon die nulhipotese dus verwerp word en die al tematiewe hipotese aanvaar word, naamlik:

dat die psigiatriese verpleegspesialis se aanbied van 'n gestruktureerde begeleidingsprogram aan psigiatriese verpleegkundiges wat die ervaring van vermoeidheid beleef, hul vlak van vermoeidheid kan verminder en hul meer daartoe in staat kan stel om hul eie probleme wat aanleiding gee tot vermoeidheid, effektief te hanteer.

Die verpleegkundiges het dus bewus geword van hul eie verantwoordelikheid in die sel thantering van hul vermocidheidsvlakke.

Die psigiatriese verpleegspesialis het ook aan hul alternatiewe hanteringsmeganismes voorgehou, sou hul eie nie effektief wees nie. Die oplossing tot die probleem van vermoeidheid le dus in die voorsiening van kennis in verband met geskikte hanteringsmeganismes soos van tocpassing op verskillende individue, maar veel belangriker is die integrering van hierdie nuutgevonde hanteringsmeganismes deur die psigiatriese verpleegkundiges. Hulle moet dus die verantwoordelikheid vir verandering in hul eie lewens aanvaar en hierdie nuutgevonde hanteringsmeganismes inoefen (Greeff, 1986:120-125).

\section{TEKORTKOMINGE VAN DIE NAVORSING}

\section{Die grootte van die steekproef}

Die steekproefgrootte is te klein om te veralgemeen na die res van die psigiatriese verpleegkundiges in die Republiek van Suid-Afrika, maar vir die bepaalde hospitaal is veralgemenings tog geldig aangesien vyftig persent van die Blanke psigiatriese verpleegkundiges wat dagdiens verrig, die ingreep ontvang het.

\section{Die steekproefrekking}

Die steekproeftrekking was by wyse van loting gedoen. 'n Meer akkurate wyse kon by wyse van 'n lukrake trekking van toevalsgetalle op 'n ewekansige steekproefwbel wees.

\section{Die toepassing van die ingreep}

Weens praktiese redes ten opsigte van personeelbeskjkbaarheid, kon die totale E1 en
E2 - groepe nie gelyktydige ingetrek word vir die anbieding van die driedaagse gestruktureerde begeleidingsprogram nie.

Dit kon moontlik tot gevolg he dat die groepe mekaar kon beïnvloed.

Die selfroltooiingsformaat van die meetinstrument

Die selfroltooiingsformat van die selfevalueringskaal kan aanleiding gee tot subjektiwiteit tydens die voltooiing of dit mag bepaal de verwagtinge by die proefpersone skep. Om laasgenoemde te beperk, was die opskrif van die selfevalueringskaal as neutraal en niksseggend gestel (Greeff, 1986: 125-128).

\section{TOEPASSINGSMOONTLIKIIEDE}

Alhoewel die navorsing slegs op die psigiatriese verpleegkundiges uitgevoer was, kan die navorsing van toepassing gemaak word op alle individue in mens - diens- professies en kan dit dus uitgebrei word na lede van die multi-dissiplinêre span. Die driedaagse gestruktureerde begeleidingsprogram kan ok van tyd tot tyd as ' $n$ indiensopleidingspro in aan verpleegkundiges gebied word, aangesien verandering volgens die beginsel van werklike interaksie nooit finaal is nie (Greeff, 1986:128).

\section{AANBEVELINGS}

Die volgende aanbevelings spruit uit die bevindinge van die navorsing:

Indien 'n gestruktureerde begeleidingsprogram ter voorkoming van vermoeidheid aangebied word, behoort daar 'n periode van minstens twee dae na afloop van die kursus te verloop alvorens die psigiatriese verpleegkundiges hul daaglikse roetine en verpligtinge in afdelings hervat.

Die selfevalueringsmateriaal behoort na afloop van pl us minus twee maande herhaal te word om te kan evalueer of die individue die aktiwiteite wat tydens die gestrukturcerde begeleidingsprogram aan hulle gebied is, in hul eie lewens geïnternaliseer het.

So 'n gestruktureerde begeleidingsprogram Ter voorkoming van vermoeidheid, behoort aan alle verpleegkundiges gebied te word sowel as aan studentverpleegkundiges wat nuut die professie betree asook aan verpleegkundiges was opnuut die professie betree. Dit kan hulle met meer paraatheid toerus om hul eie behoeftes te identifiseer, hanteringsmeganismes te evalueer en strategieè aan te leer om stres vanuit hul persoonlike en werkslewe gesond te verwerk.

'n Meetinstrument om verpleegkundiges se vermoeidheidsvlakke te evalueer behoort op 'n drie-maandelikse basis op hulle uitgevoer te word. Dit bied aan hulle die geleentheid om uit te tree vir begeleiding indien hulle dit nodig ag. So 'n meetinstrument kan dus as monitorinstrument gebruik word om verpleegkundiges se vermoeidheidsvlakke te bepaal, aangesien die werklike hantering van vermoeidheid 'n voortgesette proses is en nie eenmalig hanteer kan word nie.

'n Praktiese begeleidingsmodel wat in individucle sowel as in groepsverband toegepas kan word, behoort gekonseptualiseer te word en tot die beskikking van begeleiers gestel word. 
Groter oordeel behoort aan die dag gelê te word met die gebruik van die term "uitbranding", aangesien die oorsake van die verskynsel steeds vaag en allesinsluitend is. Die term "vermoeidheid" mag meer gepas wees.

Die verpleegkundiges behoort meer bewus gemaak te word van hul eie kwesbaarheid tot die ervaring van vermoeidheid, aangesien die ervaring nie voorkom kan word in die sin van "nie meer daar wees nie", maar wel dat indien die ervaring geidentifiseer en hanteer sou word, dit tot persoonlike en professionele verryking en groei asook effektiewer hanteringsmeganismes aanieiding kan gee.

\section{SLOTSOM}

Aangesien vermoeidheid 'n omvattende verskynsel is met uiteenlopende persoonlike en professionele oorsake en effekte, is dit nodig dat psigiatriese verpleegkundiges die wanaangepaste wyses waarop hulle stressors vanuit hul persoonlike en professionele lewens waarneem en hanteer, verander.

os wel uit die navorsing blyk, kon die aanbied van 'n gestrukturecrde begeleidingsprogram deur 'n psigiatriese verpleegspesialis die psigiatriese verpleegkundiges bewus maak van hul huidige vlak van vermoeidheid en kon alternatiewe streshanteringsmeganismes ondersoek word.

Verantwoordelikheid vir direkte en akticwe optrede kon geneem word en hul vlak van vermoeidheid kon sodoende verlaag word. Deur dus 'n kundige en ervare begeleier te hê, kon die ervaring van vermoeidheid konstruktief en opbouend hanteer word en was dit 'n geleentheid vir die psigiatriese verpleegkundiges om 'n opgawe van hul lewens- en verpleegdoelstellings te maak en hulle kon op 'n pad van verdere persoonlike en professionele groei en verryking kom. Die begeleidingsgebeure het dus 'n ervaring wat op die lange duur baic negatiewe gevolge vir die psigiatriese verpleegkundige, die pasiënt en die organisasie kon hê, omskep in 'n positiewe leergebeure en persoonlike verrykingservaring. (Greeff, 1986: 131-132).

\section{BIBLIOGRAFIE}

CRITCHLEY, DL AND MAURIN, JT 1985 : The clinical specialist in psychiatric mental health nursing : Theory research and practice. New York : John Wiley \& Son.

DE WET, JJ, MONTEITH, JL de K, VENTER, PA AND STEYN, HS. 1981: Navorsingsmetodes in die Opvoedkunde. Durban-Pretoria : Butterworth.

DOWNIE, NM AND HEATH, RW 1970 : Basic statistical methods. New York : Harper \& Row.

DU TOIT, D 1986 : Stres! Verpleging RSA, 1(5), Junie $1986: 26-27$.

GREEFF, M 1986: Begeleiding ter voorkoming van vermoeidheid by psigiatriese verpleegkundiges. Ongepublisecrde $\mathrm{M}$ Cur (Psigiatriese Verpleegkunde)-skripsie. Johannesburg : RAU.

HUYSAMEN, GK 1976 : Inferensiële statistiek en navorsingsontwerp. Pretoria: Academica.

KOTZÉ, WJ 1979 : Begeleiding in die verpleegkunde. Pretoria: SAVV.

MOORE, J 1984 : Caring for the carers. Nurses have needs too. Nursing Times, 10 Oct. 1984 : 28 - 30.

MURRAY, RB AND HUELSKOETTER, MMW 1983 : Psychiatric mental health nursing, giving emotional care. Englewood Cliffs : Prentice Hall.
NEALE, JM AND LIEBERT, RM 1980 : Science and behaviour, an introduction to methods of research. Englewood Cliffs : Prentice Hall.

ODENDAL, FF, SCHOENEES, PL, SWANEPOEL, LJ, DU TOIT, SJ AND BOOYSEN, CM 1983 : HAT Verklarende handwoordeboek van die Afrikaanse taal. Johannesburg: Perskor.

PEARSON, ES \& HARTLEY, HC 1954 : Biometrical tables for Statisticians. Vol. 1 Cambridge : University Press.

PINES, AM, ARONSON, E AND KAFRY, D 1981 : Burnout from tedium to personal growth. New York: The Free Press.

UYS, HHM AND BASSON, AA 1983 : Navorsingsmetodologie vir die verpleegkunde. Pretoria: HAUM.

VAN DER WESTHUIZEN, M 1982 : Crisis : The nurse at risk. The Lamp, 39(5), Sept./Oct. 1982 : 39 - 41

\begin{tabular}{|} 
Minrie Greeff \\
(M. CUR. (Psigiatriese Verpleegkunde); ge- \\
registreerde Algentene-, Genieenskaps-, Ge- \\
vorderde Psigiatriese Verpleegkunde, \\
Vroedvrou, Verpleegdosent en -administra- \\
teur; Lektor: Verpleegkunde - RAU \\
Marie Poggenpoel \\
(D.Phil (Verpleegkunde-Psigiatries); gereg- \\
istreerde Algeniene-, Genteenskaps-, \\
Psigiatriese Verpleegkundiges, Vroedvrou, \\
Verpleegdosent en -administrateur; Mede- \\
professor: Verpleegkunde - RAU
\end{tabular}

